\title{
Impact of postoperative reduced skeletal muscle on prognosis after recurrence in gastric cancer
}

\author{
KEITA KOUZU, HIRONORI TSUJIMOTO, HIDEKAZU SUGASAWA, YUSUKE ISHIBASHI, \\ YUJIRO ITAZAKI, SATOSHI TSUCHIYA, YOJI KISHI and HIDEKI UENO
}

Department of Surgery, National Defense Medical College, Tokorozawa, Saitama 359-0042, Japan

Received March 11, 2020; Accepted August 21, 2020

DOI: $10.3892 / \mathrm{mco} .2020 .2165$

\begin{abstract}
Little is known about the association between sarcopenia development after gastrectomy and gastric cancer prognosis after recurrence. The present study retrospectively examined the effects of decreased psoas muscle index (PMI) on post-recurrence prognosis after gastrectomy. A total of 67 patients with gastric cancer recurrence were included in the present study. PMI at pre-operation and recurrence were calculated, and 25 patients whose PMI reduction rate value was lower than the cutoff values (male $=0.766$ and female $=0.704$ ) were classified into the sarcopenia group and 42 patients into the non-sarcopenia group. There were no significant differences between the groups regarding age, sex, pathological stage, and nutrition and inflammation indices at the time of recurrence. Post-recurrence overall survival (OS) was significantly shorter in the sarcopenia group compared with the non-sarcopenia group $(\mathrm{P}<0.001)$. The post-recurrence survival rate was significantly worse in the sarcopenia group compared with the non-sarcopenia group $(\mathrm{P}<0.001)$. In multivariate analysis, sarcopenia $(\mathrm{HR}=5.04)$ and the total courses of chemotherapy after recurrence $(\mathrm{HR}=3.88)$ were independent unfavorable prognostic factors. In conclusion, sarcopenia and fewer total courses of post-recurrence chemotherapy were poor prognostic factors after gastric cancer recurrence. To improve prognosis, preventing sarcopenia development after gastrectomy is required.
\end{abstract}

\section{Introduction}

Despite ongoing advances in diagnostics, operative technique, and treatment strategy for the decades, gastric cancer remains one of the most common cancers in the world and a lethal disease (1). Gastrectomy for gastric cancer is essential for improving the survival rate, it may cause persistent

Correspondence to: Professor Hironori Tsujimoto, Department of Surgery, National Defense Medical College, 3-2 Namiki, Tokorozawa, Saitama 359-0042, Japan

E-mail: tsujihi@ndmc.ac.jp

Key words: gastric cancer, chemotherapy, sarcopenia, prognosis functional disorders such as reduced amount of oral intake, insulin resistance, increased protein catabolism, and metabolic changes, leading to weight loss and the development of sarcopenia (2). It is reported that preoperative sarcopenia has been associated with long-term prognosis as well as short-term outcomes such as the development of postoperative pneumonia, poor activities of daily living, longer hospital stay, and the incidence of postoperative complications (3-10), which may restrict the following treatment options (11). Treatment option for patient with recurrence of gastric cancer after gastrectomy is limited to chemotherapy or best supportive care. It is known that sarcopenia could influence on pharmacokinetics of chemotherapy which could be associated with adverse effects of chemotherapy in several cancers (4). However, little is known about the effects of reduced skeletal muscle volume after gastrectomy on prognosis and treatment strategy after the recurrence of gastric cancer. In the present study, we investigated the effects of reduced skeletal muscle volume after gastrectomy on the treatment and prognosis in patients with recurrent gastric cancer.

\section{Materials and methods}

Patients. The study protocol was approved by the Institutional Review Board of National Defense Medical College (Saitama, Japan). Of the 553 patients who underwent radical gastrectomy for gastric cancer at the National Defense Medical College between 2011 and 2016, 67 patients who had gastric cancer recurrence were included in this study. We retrospectively evaluated the clinicopathological findings, serum albumin levels, C-reactive protein (CRP), total cholesterol, and neutrophil and lymphocyte counts at the time of preoperative and recurrence of gastric cancer. In addition, the neutrophil-lymphocyte ratio (NLR), the CRP-albumin ratio (CAR), the controlling nutrition status (CONUT) score, the prognostic nutritional index (PNI), and the modified Glasgow prognostic (mGPS) score were calculated as markers of nutrition or inflammation.

The tumor pathological findings were recorded in accordance with the third English edition of the Japanese Classification of Gastric Carcinoma, edited by the Japanese Gastric Cancer Association (12). All patients were followed-up using an oncologically appropriate plan on a per-patient basis. 


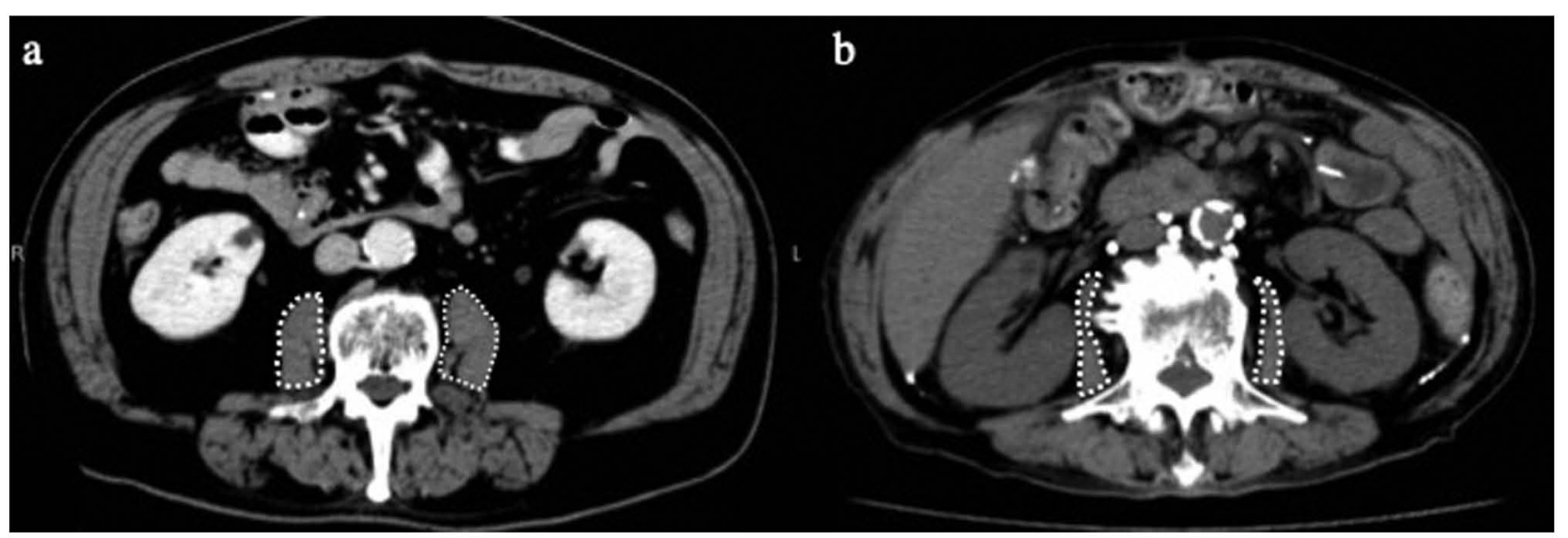

Figure 1. Sarcopenia was defined as the case with less PMI reduction rate value than the sex-specific cut-off values. The psoas muscle mass was measured using a manually traced area as presented by the dotted line. (a) non-sarcopenia case and (b) sarcopenia case. PMI, psoas muscle index.

For patients with stage II or III disease, postoperative adjuvant chemotherapy with $\mathrm{S}-1$ ( $80 \mathrm{mg} / \mathrm{m}^{2} /$ day) was recommended for 1 year. In 45 cases of pathological stage II or III gastric cancer patients, 26 cases $(57.8 \%)$ received adjuvant chemotherapy. There was no significant correlation between age and receiving adjuvant chemotherapy.

Definition of sarcopenia. The psoas muscle index (PMI: $\mathrm{cm}^{2} / \mathrm{m}^{2}$ ) was calculated from CT images (Aquilion 64; Toshiba Medical Systems) and the psoas muscle cross-sectional area at the third lumbar vertebra (L3) normalized length preoperatively and at the recurrence of gastric cancer by a physician who was blinded to the clinicopathological characteristics of the patients (Fig. 1) $(13,14)$. The reduction rate of PMI from the preoperative value to that at the recurrence of gastric cancer was calculated. The patients were divided into two groups by the cutoff value using area under the receiver operating characteristic curves (ROC); the sarcopenia group ( $n=25$ patients) had less than the cutoff value of the reduction rate of PMI (male $=0.766$ and female $=0.704)$, and the non-sarcopenia group ( $\mathrm{n}=42$ patients) had more than the cutoff value (Fig. 2). The median value of the total cohort was 0.793 .

Statistical analyses. All statistical analyses were performed using the $\mathrm{JMP}^{\circledR}$ Pro 14.0 .0 software package (SAS Institute Inc.). The Student's t-test and Pearson's Chi-square test were performed, as appropriate. A receiver operating characteristics (ROC) curve was constructed to estimate the optimal cutoff value of the reduction of PMI. Survival rates were obtained by the Kaplan-Meier method, and the statistical significance was determined by the log-rank test.

Univariate and multivariate analyses were performed using the Cox proportional hazards regression model. The data are expressed as mean \pm standard deviation. A P-value of $<0.05$ was considered statistically significant.

\section{Results}

Patient characteristics. Patients' clinical factors at the recurrence of gastric cancer and pathological factors diagnosed from resected specimens are shown in Table I. There were no significant differences in age, sex, Charlson Comorbidity Index score, and surgical procedure including reconstruction methods between the two groups. The sarcopenia group had a higher body weight and body mass index (BMI) than did the non-sarcopenia group. In addition, the reduction rates of body weight and BMI due to the recurrence of gastric cancer in the sarcopenia group were higher than those of the non-sarcopenia group. There was no significant difference in the pathological factors between the two groups except for tumor depth. The NLR, CAR, CONUT score, PNI, and mGPS at the recurrence of gastric cancer were not significantly different between the two groups (Table II). There was no significant difference in the time between gastrectomy and recurrence, the number of patients who received adjuvant chemotherapy and chemotherapy after the recurrence, the number of discontinued chemotherapies due to adverse effect, the number of chemotherapy regimens after recurrence, the kind of basic chemotherapy after recurrence, and the total courses of chemotherapies between the two groups. The sarcopenia group had a significantly shorter OS from recurrence than did the non-sarcopenia group (median survival time, interquartile range: $118,43.5-180.5$ vs. $300,133.8-636.3$ days, $\mathrm{P}<0.001)$.

Prognostic factors. The survival rate from the time of recurrence in the sarcopenia group was significantly worse than that in the non-sarcopenia group (3-year OS $6.0 \%$ vs. $21.0 \%$, $\mathrm{P}<0.001$; Fig. 3). Univariate and multivariate analyses that might affect the survival rate from the time of the recurrence of gastric cancer were shown in Table III. Univariate analysis demonstrated that the total courses of chemotherapy after recurrence $<5$ [hazard ratio $(\mathrm{HR})=3.82$ ], sarcopenia $(\mathrm{HR}=2.66), \mathrm{NLR} \geq 3.0(\mathrm{HR}=2.63)$, and $\mathrm{PNI} \leq 40(\mathrm{HR}=2.59)$ were significantly associated with the prognosis after recurrence. The sarcopenia group more frequently had peritoneal recurrence, which didn't affect prognosis.

Multivariate analysis revealed that sarcopenia at the recurrence $(\mathrm{HR}=5.04)$ and the total courses of chemotherapy after recurrence $(\mathrm{HR}=3.88)$ were independent unfavorable prognostic factors.

Table IV shows univariate and multivariate analysis for the OS from the time at recurrence among the difference time 


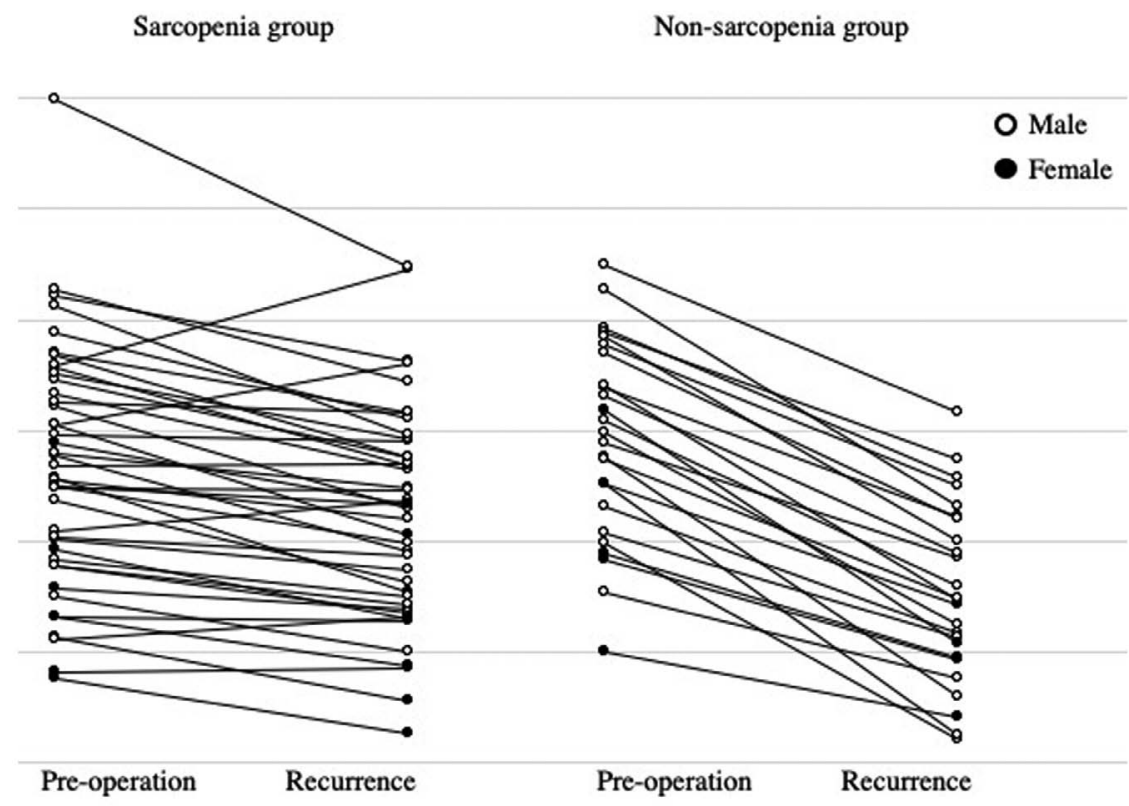

Figure 2. Changes in PMI from preoperative to recurrence in all patients; the sarcopenia group exhibited $<$ cutoff value of the reduction rate of PMI (male $=0.804$ and female $=0.733$ ), and the non-sarcopenia group exhibited $>$ the cutoff value. Open circles represent male cases and filled circles represent female cases. PMI, psoas muscle index.

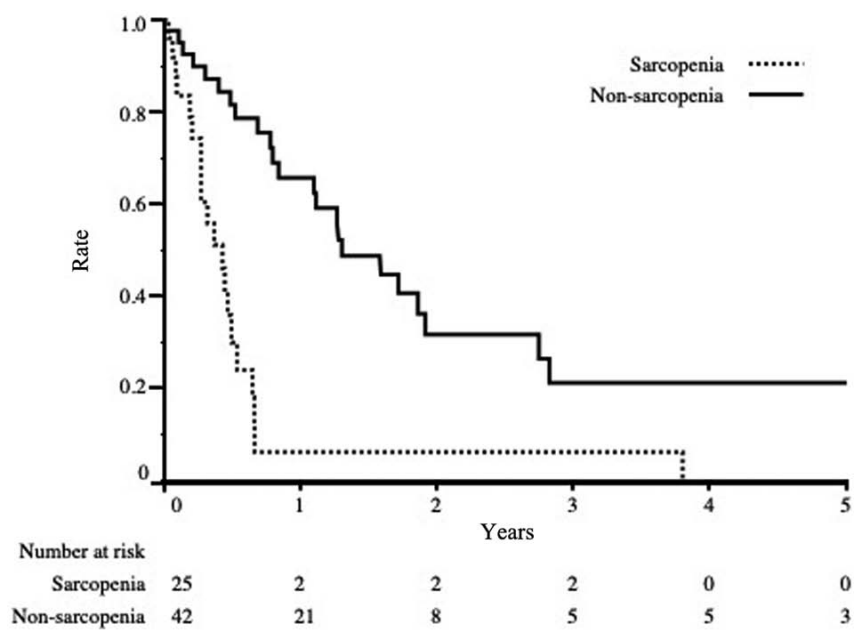

Figure 3. The overall survival from the time of recurrence. Log-rank test, $\mathrm{P}<0.05$.

of sarcopenia. Sarcopenia at the recurrence and the reduction rate of PMI from surgery to the recurrence were selected as the independent poor prognostic factors via multivariate analysis, but preoperative sarcopenia was not.

\section{Discussion}

In the present study, we demonstrated that the high reduction rate of PMI from the preoperative value to that at the recurrence of gastric cancer and the fewer courses of chemotherapy performed after recurrence were independently associated with poor prognosis after the recurrence.

Since Rosenberg has reported the concept of sarcopenia in 1997, and many studies have evaluated the associations between sarcopenia and clinical factors, such as poor quality of life, aspiration pneumonia, osteoporosis, swallowing function, and respiratory function (15). In patients with malignancies, sarcopenia is more likely to be developed due to increased protein catabolism, inflammatory reactions, metabolic abnormalities, and poor oral intake and may be associated with cancer cachexia. Many recent studies have shown that the frequency of serious postoperative complications was high and the long-term prognosis was poor in gastric cancer patients with preoperative sarcopenia $(5-7,9,10)$. In addition, postoperative loss of the muscle mass affects the continuation rate of postoperative adjuvant chemotherapy, especially in the elderly, because of increased severe adverse events $(16,17)$. However, no study has evaluated the relationship between prognosis after the recurrence and the reduction of skeletal muscle mass after gastrectomy. This study indicated that the reduction of PMI was a risk factor of poor OS after the recurrence of gastric cancer, which is consistent with a previous report that skeletal muscle loss during postoperative adjuvant chemotherapy is associated with poor prognosis (18).

We also demonstrated that patients who failed to continue chemotherapy more than five courses after the recurrence of gastric cancer had a poor prognosis. There are several factors affecting the continuity of chemotherapy after the recurrence, i.e., adverse events, age, performance status, the amounts of oral intakes, economic problem, and other social circumstances (19). Physicians can intervene the continuity of chemotherapy by providing appropriate nutritional management and preventing loss of skeletal muscle mass at the time of recurrence, which may be associated with longer survival after the recurrence of gastric cancer.

Preoperative exercises and nutritional support programs were effective for increasing total caloric intake, protein, and grip strength, maintaining skeletal muscle volume and 
Table I. Patient's clinicopathological factors.

\begin{tabular}{|c|c|c|c|c|}
\hline Characteristic & Sarcopenia $(n=25,37.3 \%)$ & Non-Sarcopenia $(n=42,62.7 \%)$ & Total $(\mathrm{n}=67)$ & P-value \\
\hline Age & $72.1 \pm 7.8$ & $70.0 \pm 8.6$ & $70.8 \pm 8.3$ & 0.393 \\
\hline Sex & & & & 0.718 \\
\hline Male & 20 & 32 & 52 & \\
\hline Female & 5 & 10 & 15 & \\
\hline \multicolumn{5}{|l|}{ Body weight (kg) } \\
\hline Preoperatively & $55.4 \pm 8.9$ & $59.5 \pm 9.8$ & $57.9 \pm 9.6$ & 0.082 \\
\hline At the time of recurrence & $46.2 \pm 8.1$ & $51.2 \pm 7.9$ & $49.3 \pm 8.3$ & $0.014^{\mathrm{a}}$ \\
\hline Recurrence/preoperatively & $0.8 \pm 0.1$ & $0.9 \pm 0.1$ & $0.9 \pm 0.1$ & $0.422^{\mathrm{b}}$ \\
\hline \multicolumn{5}{|l|}{ Body mass index $\left(\mathrm{kg} / \mathrm{m}^{2}\right)$} \\
\hline Preoperatively & $21.3 \pm 2.9$ & $22.6 \pm 3.2$ & $22.1 \pm 3.1$ & 0.071 \\
\hline At the time of recurrence & $17.7 \pm 2.2$ & $19.5 \pm 2.6$ & $18.8 \pm 2.6$ & $0.010^{\mathrm{a}}$ \\
\hline Recurrence/preoperatively & $0.8 \pm 0.1$ & $0.9 \pm 0.1$ & $0.9 \pm 0.1$ & 0.338 \\
\hline \multicolumn{5}{|l|}{ Psoas muscle index } \\
\hline Preoperatively & $3.9 \pm 0.9$ & $3.7 \pm 1.1$ & $3.8 \pm 1.0$ & 0.223 \\
\hline At the time of recurrence & $2.5 \pm 0.8$ & $3.2 \pm 1.0$ & $3.0 \pm 1.0$ & $0.005^{\mathrm{a}}$ \\
\hline Recurrence/Preoperatively & $0.6 \pm 0.1$ & $0.9 \pm 0.1$ & $0.8 \pm 0.2$ & $<0.001^{\mathrm{a}}$ \\
\hline CCI score $2 \leq$ & & & & 0.630 \\
\hline Yes & 6 & 8 & 14 & \\
\hline No & 19 & 34 & 53 & \\
\hline Tumor location U/M/L & & & & 0.579 \\
\hline $\mathrm{U}$ & 11 & 15 & 26 & \\
\hline M & 9 & 12 & 21 & \\
\hline $\mathrm{L}$ & 5 & 15 & 20 & \\
\hline Histology int/dif/other & & & & 0.210 \\
\hline Int & 14 & 18 & 32 & \\
\hline Dif & 8 & 22 & 30 & \\
\hline Other & 3 & 2 & 5 & \\
\hline Tumor depth & & & & 0.418 \\
\hline pT1 & $4(16.0 \%)$ & $3(7.1 \%)$ & $7(10.5 \%)$ & \\
\hline pT2 & $3(12.0 \%)$ & $3(7.1 \%)$ & $6 \quad(9.0 \%)$ & \\
\hline pT3 & $7(28.0 \%)$ & $19(45.2 \%)$ & $26(38.8 \%)$ & \\
\hline pT4 & $11(44.0 \%)$ & $17(40.5 \%)$ & $28(41.8 \%)$ & \\
\hline Lymph node metastasis & & & & 0.978 \\
\hline $\mathrm{pNO}$ & $5(20.0 \%)$ & $8(19.1 \%)$ & $13(19.4 \%)$ & \\
\hline $\mathrm{pN} 1$ & $4(16.0 \%)$ & $8(19.1 \%)$ & $12(17.9 \%)$ & \\
\hline $\mathrm{pN} 2$ & $6(24.0 \%)$ & $11(26.2 \%)$ & $17(25.4 \%)$ & \\
\hline pN3 & $10(40.0 \%)$ & $15(35.7 \%)$ & $25(37.3 \%)$ & \\
\hline Pathological cancer stage & & & & 0.267 \\
\hline pStageI & $3(12.0 \%)$ & $3(7.2 \%)$ & $6(9.1 \%)$ & \\
\hline pStageII & $6(24.0 \%)$ & $12(28.6 \%)$ & $18(27.3 \%)$ & \\
\hline pStageIII & $16(64.0 \%)$ & $27(64.3 \%)$ & $43(63.6 \%)$ & \\
\hline Lymphatic invasion & & & & 0.613 \\
\hline Ly0 & 2 & 5 & 7 & \\
\hline Ly1 & 23 & 37 & 60 & \\
\hline Venous invasion & & & & 0.429 \\
\hline V0 & 4 & 4 & 8 & \\
\hline V1 & 21 & 38 & 59 & \\
\hline DG/TG/other & & & & 0.161 \\
\hline DG & 6 & 19 & 25 & \\
\hline TG & 17 & 22 & 39 & \\
\hline Other & 2 & 1 & 3 & \\
\hline
\end{tabular}


Table I. Continued.

\begin{tabular}{|c|c|c|c|c|}
\hline Characteristic & Sarcopenia $(\mathrm{n}=25,37.3 \%)$ & Non-Sarcopenia $(\mathrm{n}=42,62.7 \%)$ & Total $(n=67)$ & P-value \\
\hline Open/laparoscopy & & & & 0.161 \\
\hline Open & 18 & 23 & 41 & \\
\hline Laparoscopy & 7 & 19 & 26 & \\
\hline Billroth-I/Roux-en-Y/other & & & & 0.130 \\
\hline Billroth-I & 6 & 15 & 21 & \\
\hline Roux-en-Y & 2 & 27 & 44 & \\
\hline Other & 17 & 0 & 2 & \\
\hline Recurrence pattern & & & & 0.455 \\
\hline Peritoneal & $9(36.0 \%)$ & $9(7.1 \%)$ & $18(26.9 \%)$ & \\
\hline Hematogenous & $6(24.0 \%)$ & $17(7.1 \%)$ & $23(34.3 \%)$ & \\
\hline Lymph node & $6(24.0 \%)$ & $11(7.1 \%)$ & $17(25.4 \%)$ & \\
\hline Local & $2(8.0 \%)$ & $1(7.1 \%)$ & $3(4.5 \%)$ & \\
\hline Other & $2(8.0 \%)$ & $4(45.2 \%)$ & $6(8.9 \%)$ & \\
\hline
\end{tabular}

U, upper third; M, middle third; L, lower third; Int, intestinal type; Dif, diffuse type; DG, Distal gastrectomy; TG, Total gastrectomy; CCI, Charlson comorbidity index; ${ }^{\mathrm{a}} \mathrm{P}<0.05$. Data are expressed as the mean \pm standard deviation.

Table II. Patient's characteristics at the time of recurrence of gastric cancer.

\begin{tabular}{|c|c|c|c|c|}
\hline Characteristic & $\begin{array}{c}\text { Sarcopenia } \\
(\mathrm{n}=25,37.3 \%)\end{array}$ & $\begin{array}{l}\text { Non-Sarcopenia } \\
(\mathrm{n}=42,62.7 \%)\end{array}$ & $\begin{array}{l}\text { Total } \\
(n=67)\end{array}$ & P-value \\
\hline \multicolumn{5}{|l|}{ Neutrophil lymphocyte ratio } \\
\hline Preoperatively & $3.0 \pm 2.4$ & $3.5 \pm 2.8$ & $3.3 \pm 2.6$ & 0.828 \\
\hline At the time of recurrence & $4.2 \pm 3.1$ & $4.6 \pm 4.7$ & $4.5 \pm 4.1$ & 0.589 \\
\hline \multicolumn{5}{|l|}{ CAR } \\
\hline Preoperatively & $0.3 \pm 0.4$ & $0.1 \pm 0.2$ & $0.2 \pm 0.3$ & 0.213 \\
\hline At the time of recurrence & $0.7 \pm 1.0$ & $0.5 \pm 0.6$ & $0.6 \pm 0.8$ & 0.474 \\
\hline \multicolumn{5}{|l|}{ CONUT score } \\
\hline Preoperatively & $2.3 \pm 1.1$ & $2.5 \pm 1.3$ & $2.4 \pm 1.2$ & 0.597 \\
\hline At the time of recurrence & $4.8 \pm 2.8$ & $3.0 \pm 1.7$ & $3.9 \pm 2.5$ & 0.062 \\
\hline \multicolumn{5}{|l|}{ Prognostic nutritional index } \\
\hline Preoperatively & $37.2 \pm 9.5$ & $35.9 \pm 13.3$ & $36.4 \pm 11.7$ & 0.746 \\
\hline At the time of recurrence & $39.7 \pm 7.5$ & $43.7 \pm 9.0$ & $42.1 \pm 8.6$ & 0.114 \\
\hline \multicolumn{5}{|l|}{ Modified GPS score } \\
\hline Preoperatively & $0.4 \pm 0.7$ & $0.5 \pm 0.7$ & $0.5 \pm 0.7$ & 0.927 \\
\hline At the time of recurrence & $1.2 \pm 0.7$ & $1.0 \pm 0.6$ & $1.1 \pm 0.7$ & 0.180 \\
\hline Adjuvant chemotherapy & & & & 0.874 \\
\hline Yes & 8 & 16 & 24 & \\
\hline No & 17 & 26 & 43 & \\
\hline Discontinued adjuvant chemotherapy due to adverse effect & $6(75.0 \%)$ & $10(62.5 \%)$ & $16(66.7 \%)$ & 0.540 \\
\hline Duration from gastrectomy to recurrence (day) & $572.9 \pm 513.2$ & $444.8 \pm 331.0$ & $492.6 \pm 409.5$ & 0.484 \\
\hline Chemotherapy after recurrence & & & & 0.729 \\
\hline Yes & 12 & 22 & 34 & \\
\hline No & 13 & 20 & 33 & \\
\hline 1st line regimen after recurrence & & & & 0.100 \\
\hline Pyrimidine fluoride & 8 & 20 & 28 & \\
\hline Taxane & 2 & 2 & 4 & \\
\hline Other & 2 & 0 & 2 & \\
\hline
\end{tabular}


Table II. Continued.

\begin{tabular}{|c|c|c|c|c|}
\hline Characteristic & $\begin{array}{c}\text { Sarcopenia } \\
(\mathrm{n}=25,37.3 \%)\end{array}$ & $\begin{array}{c}\text { Non-Sarcopenia } \\
(\mathrm{n}=42,62.7 \%)\end{array}$ & $\begin{array}{l}\text { Total } \\
(n=67)\end{array}$ & P-value \\
\hline Number of chemotherapy regimens after recurrence & $1.6 \pm 0.8$ & $1.7 \pm 1.0$ & $1.7 \pm 0.9$ & 0.855 \\
\hline Total courses of chemotherapy after recurrence & $3.7 \pm 2.4$ & $7.5 \pm 5.6$ & $6.3 \pm 5.1$ & 0.092 \\
\hline Discontinued chemotherapy due to adverse effect & $6(50.0 \%)$ & $7(31.8 \%)$ & $13(38.2 \%)$ & 0.297 \\
\hline Overall survival from the recurrence of gastric cancer (day) & $169.0 \pm 52.8$ & $492.9 \pm 83.4$ & $372.0 \pm 58.8$ & $<0.001$ \\
\hline
\end{tabular}

CAR, C-reactive protein Albumin ratio; CONUT, controlling nutrition status; GPS, Glasgow Prognostic Score. Data are expressed as the mean \pm standard deviation.

Table III. Prognostic factor for the overall survival from the time at recurrence.

\begin{tabular}{|c|c|c|c|c|c|c|}
\hline \multirow[b]{2}{*}{ Characteristic } & \multicolumn{3}{|c|}{ Univariate analysis } & \multicolumn{3}{|c|}{ Multivariate analysis } \\
\hline & HR & $95 \% \mathrm{CI}$ & P-value & HR & $95 \% \mathrm{CI}$ & P-value \\
\hline $\begin{array}{l}\text { Age } \\
\geq 70 \text { years old }\end{array}$ & 1.69 & $0.91-3.22$ & 0.096 & & & \\
\hline $\begin{array}{l}\text { Body weight reduction rate } \\
\geq \text { Median }\end{array}$ & 1.24 & $0.67-2.28$ & 0.490 & & & \\
\hline $\begin{array}{l}\text { Body mass index reduction rate } \\
\geq \text { Median }\end{array}$ & 1.21 & $0.65-2.23$ & 0.530 & & & \\
\hline $\begin{array}{l}\text { CCI score } \\
\geq 2\end{array}$ & 0.90 & $0.37-1.92$ & 0.802 & & & \\
\hline $\begin{array}{l}\text { Tumor depth } \\
\geq \mathrm{pT} 3\end{array}$ & 0.71 & $0.35-1.66$ & 0.404 & & & \\
\hline $\begin{array}{l}\text { Lymph node metastasis } \\
\geq \mathrm{pN} 2\end{array}$ & 1.65 & $0.88-3.24$ & 0.117 & & & \\
\hline $\begin{array}{l}\text { Lymphatic invasion } \\
\text { Ly1 }\end{array}$ & 0.99 & $0.45-2.62$ & 0.984 & & & \\
\hline $\begin{array}{l}\text { Venous invasion } \\
\text { V1 }\end{array}$ & 0.95 & $0.43-2.52$ & 0.908 & & & \\
\hline $\begin{array}{l}\text { Neutro Lymph ratio } \\
\geq 3.0\end{array}$ & 2.63 & $1.28-5.53$ & $0.008^{\mathrm{a}}$ & 1.48 & $0.40-5.01$ & 0.544 \\
\hline $\begin{array}{l}\text { CONUT score } \\
\geq 4\end{array}$ & 2.26 & $0.90-6.20$ & 0.084 & & & \\
\hline $\begin{array}{l}\text { Prognostic Nutritional Index } \\
\leq 40\end{array}$ & 2.59 & $1.23-5.50$ & $0.012^{\mathrm{a}}$ & 1.25 & $0.33-5.01$ & 0.746 \\
\hline $\begin{array}{l}\text { modified GPS score } \\
\geq 1\end{array}$ & 1.91 & $0.90-4.70$ & 0.097 & & & \\
\hline $\begin{array}{l}\text { Sarcopenia } \\
\text { Yes }\end{array}$ & 4.18 & $2.17-8.07$ & $<0.001^{\mathrm{a}}$ & 5.04 & $1.28-22.61$ & $0.021^{\mathrm{a}}$ \\
\hline $\begin{array}{l}\text { Adjuvant chemotherapy } \\
\text { No }\end{array}$ & 1.05 & $0.58-1.93$ & 0.872 & & & \\
\hline $\begin{array}{l}\text { Recurrence site } \\
\text { Peritoneal }\end{array}$ & 1.49 & $0.75-2.80$ & 0.246 & & & \\
\hline $\begin{array}{l}\text { Chemotherapy after recurrence } \\
\text { No }\end{array}$ & 1.32 & $0.71-2.43$ & 0.376 & & & \\
\hline Chemotherapy regimen after recurrence & 0.45 & $0.16-1.59$ & 0.192 & & & \\
\hline
\end{tabular}

Pyrimidine fluoride 
Table III. Continued.

\begin{tabular}{|c|c|c|c|c|c|c|}
\hline \multirow[b]{2}{*}{ Characteristic } & \multicolumn{3}{|c|}{ Univariate analysis } & \multicolumn{3}{|c|}{ Multivariate analysis } \\
\hline & HR & $95 \% \mathrm{CI}$ & P-value & HR & $95 \% \mathrm{CI}$ & P-value \\
\hline $\begin{array}{l}\text { Number of regimens after recurrence } \\
<2\end{array}$ & 1.13 & $0.50-2.58$ & 0.762 & & & \\
\hline $\begin{array}{l}\text { Total courses of chemotherapy after recurrence } \\
<5\end{array}$ & 3.82 & $1.33-11.42$ & $0.013^{\mathrm{a}}$ & 3.88 & $1.19-13.69$ & $0.025^{\mathrm{a}}$ \\
\hline
\end{tabular}

HR, hazard ratio; CI, confidence interval; CRP, C-reactive protein; CONUT, controlling nutrition status; GPS, Glasgow Prognostic Score; CCI, Charlson comorbidity index. ${ }^{a} \mathrm{P}<0.05$.

Table IV. Univariate and multivariate analysis for the overall survival from the time at recurrence among the difference time of sarcopenia.

\begin{tabular}{|c|c|c|c|c|c|c|c|}
\hline & & \multicolumn{3}{|c|}{ Univariate analysis } & \multicolumn{3}{|c|}{ Multivariate analysis } \\
\hline & & $\mathrm{HR}$ & $95 \% \mathrm{CI}$ & P-value & HR & $95 \% \mathrm{CI}$ & P-value \\
\hline Sarcopenia by skeletal muscle mass reduction rate & Yes & 4.18 & $2.17-8.07$ & $<0.001^{\mathrm{a}}$ & 3.05 & $1.44-6.48$ & $0.004^{\mathrm{a}}$ \\
\hline Preoperative sarcopenia & Yes & 0.93 & $0.51-1.73$ & 0.813 & 0.80 & $0.39-1.67$ & 0.551 \\
\hline Sarcopenia at the time of recurrence & Yes & 3.58 & $1.78-7.42$ & $<0.001^{\mathrm{a}}$ & 3.05 & $1.30-7.31$ & $0.010^{\mathrm{a}}$ \\
\hline
\end{tabular}

HR, hazard ratio; CI, confidence interval. ${ }^{a} \mathrm{P}<0.05$.

improving postoperative outcomes in patients with gastric cancer $(19,20)$. However, there were few reports on the effects of postoperative nutritional supports on the postoperative development of sarcopenia and outcome. In addition, it has been reported that subtotal gastrectomy for the upper third of gastric cancer had advantages over total gastrectomy in terms of maintaining weight and nutritional status $(20,21)$. Thus, it will be essential to ensure thorough nutritional management after surgery, as well as surgical procedures, for maintaining skeletal muscle volume and nutritional status at the recurrence of gastric cancer.

In the present study, we also evaluated the NLR, CAR, PNI, CONUT, and mGPS at the recurrence of gastric cancer, which were well known to be preoperative prognostic markers in various malignancies (22-26). We demonstrated that these markers were not associated with prognosis when the values at the recurrence were used, indicating the importance of preoperative value but not at the recurrence.

We compared the clinical importance of the sarcopenia preoperatively, at the recurrence, and the reduction rate of PMI from surgery to the recurrence. Sarcopenia at the recurrence and the reduction rate of PMI from surgery to the recurrence were selected as the independent poor prognostic factors by multivariate analysis.

This study has several potential limitations. The retrospective design of the study and relatively small number of patients in this study may have resulted in bias. In addition, we did not evaluate the relation of amounts of oral intake and the exercise after gastrectomy to the occurrence of gastric cancer, which made it difficult to determine whether skeletal muscle loss was caused by eating disorder after gastrectomy or with the progression of cancer.

In conclusion, fewer total courses of chemotherapy after recurrence and sarcopenia were poor prognostic factors for patients with gastric cancer recurrence. Our data suggested that prospective interventional study to prevent the reduction of skeletal muscle volume should be promising for improving survival after the recurrence of gastric cancer.

\section{Acknowledgements}

Not applicable.

\section{Funding}

No funding was received.

\section{Availability of data and materials}

The datasets used and/or analyzed during the present study are available from the corresponding author on reasonable request.

\section{Authors contributions}

KK, HT, HS, YIt, YIs, ST, YK and HU contributed to the study conception and design. Material preparation and data collection and analysis were performed by KK. The first draft of the manuscript was written by KK and HT, and all 
authors commented on previous versions of the manuscript. All authors read and approved the final manuscript.

\section{Ethics approval and consent to participate}

All procedures followed were in accordance with the Helsinki Declaration of 1964 and later versions. The study protocol was approved by the Institutional Review Board of the National Defense Medical College, and written informed consent was obtained from every patient.

\section{Patient consent for publication}

Informed consent for publication was obtained from every patient.

\section{Competing interests}

The authors declare that they have no competing interests.

\section{References}

1. Siegel RL, Miller KD and Jemal A: Cancer statistics, 2020. CA Cancer J Clin 70: 7-30, 2020.

2. Cruz-Jentoft AJ, Baeyens JP, Bauer JM, Boirie Y, Cederholm T, Landi F, Martin FC, Michel JP, Rolland Y, Schneider SM, et al: Sarcopenia: European consensus on definition and diagnosis: Report of the European working group on sarcopenia in older people. Age Ageing 39: 412-423, 2010.

3. Nagata $K$, Tsujimoto $H$, Nagata $H$, Harada M, Ito $N$, Kanematsu K, Nomura S, Horiguchi $\mathrm{H}$, Hiraki S, Hase K, et al: Impact of reduced skeletal muscle volume on clinical outcome after esophagectomy for esophageal cancer: A retrospective study. Medicine (Baltimore) 97: el1450, 2018.

4. Antoun S, Borget I and Lanoy E: Impact of sarcopenia on the prognosis and treatment toxicities in patients diagnosed with cancer. Curr Opin Support Palliat Care 7: 383-389, 2013.

5. Fukuda Y, Yamamoto K, Hirao M, Nishikawa K, Nagatsuma Y, Nakayama T, Tanikawa S, Maeda S, Uemura M, Miyake M, et al: Sarcopenia is associated with severe postoperative complications in elderly gastric cancer patients undergoing gastrectomy. Gastric Cancer 19: 986-993, 2016.

6. Huang DD, Chen XX, Chen XY, Wang SL, Shen X, Chen XL, $\mathrm{Yu} \mathrm{Z}$ and Zhuang CL: Sarcopenia predicts 1 -year mortality in elderly patients undergoing curative gastrectomy for gastric cancer: A prospective study. J Cancer Res Clin Oncol 142: 2347-2356, 2016.

7. Kawamura T, Makuuchi R, Tokunaga M, Tanizawa Y, Bando E, Yasui H, Aoyama T, Inano $\mathrm{T}$ and Terashima M: Long-term outcomes of gastric cancer patients with preoperative sarcopenia. Ann Surg Oncol 25: 1625-1632, 2018.

8. Ongaro E, Buoro V, Cinausero M, Caccialanza R, Turri A, Fanotto V, Basile D, Vitale MG, Ermacora P, Cardellino GG, et al: Sarcopenia in gastric cancer: When the loss costs too much. Gastric Cancer 20: 563-572, 2017.

9. Wang SL, Zhuang CL, Huang DD, Pang WY, Lou N, Chen FF, Zhou CJ, Shen X and Yu Z: Sarcopenia adversely impacts postoperative clinical outcomes following gastrectomy in patients with gastric cancer: A prospective study. Ann Surg Oncol 23: 556-564, 2016

10. Zhuang CL, Huang DD, Pang WY, Zhou CJ, Wang SL, Lou N, Ma LL, Yu Z and Shen X: Sarcopenia is an independent predictor of severe postoperative complications and long-term survival after radical gastrectomy for gastric cancer: Analysis from a large-scale cohort. Medicine (Baltimore) 95: e3164, 2016.

11. Gosney MA: Clinical assessment of elderly people with cancer. Lancet Oncol 6: 790-797, 2005.

12. Japanese Gastric Cancer Association: Japanese classification of gastric carcinoma: 3rd English edition. Gastric Cancer 14: 101-112, 2011.
13. Hamaguchi Y, Kaido T, Okumura S, Kobayashi A, Hammad A, Tamai Y, Inagaki N and Uemoto S: Proposal for new diagnostic criteria for low skeletal muscle mass based on computed tomography imaging in Asian adults. Nutrition 32: 1200-1205, 2016.

14. Mourtzakis M, Prado CM, Lieffers JR, Reiman T, McCargar LJ and Baracos VE: A practical and precise approach to quantification of body composition in cancer patients using computed tomography images acquired during routine care. Appl Physiol Nutr Metab 33: 997-1006, 2008.

15. Rosenberg IH: Sarcopenia: Origins and clinical relevance. J Nutr 127 (5 Suppl): 990S-991S, 1997.

16. Aoyama T, Kawabe T, Fujikawa H, Hayashi T, Yamada T, Tsuchida K, Yukawa N, Oshima T, Rino Y, Masuda M, et al: Loss of lean body mass as an independent risk factor for continuation of S-1 adjuvant chemotherapy for gastric cancer. Ann Surg Oncol 22: 2560-2566, 2015.

17. Shen Y, Hao Q, Zhou J and Dong B: The impact of frailty and sarcopenia on postoperative outcomes in older patients undergoing gastrectomy surgery: A systematic review and meta-analysis. BMC Geriatr 17: 188, 2017.

18. Sugiyama K, Narita Y, Mitani S, Honda K, Masuishi T, Taniguchi H, Kadowaki S, Ura T, Ando M, Tajika $M$ and Muro K: Baseline sarcopenia and skeletal muscle loss during chemotherapy affect survival outcomes in metastatic gastric cancer. Anticancer Res 38: 5859-5866, 2018.

19. Japanese Gastric Cancer Association: Japanese gastric cancer treatment guidelines 2014 (ver. 4). Gastric Cancer 20: 1-19, 2017.

20. Yamamoto K, Nagatsuma Y, Fukuda Y, Hirao M, Nishikawa K, Miyamoto A, Ikeda M, Nakamori S, Sekimoto M, Fujitani K and Tsujinaka T: Effectiveness of a preoperative exercise and nutritional support program for elderly sarcopenic patients with gastric cancer. Gastric Cancer 20: 913-918, 2017.

21. Kosuga T, Hiki N, Nunobe S, Noma H, Honda M, Tanimura S, Sano T and Yamaguchi T: Feasibility and nutritional impact of laparoscopy-assisted subtotal gastrectomy for early gastric cancer in the upper stomach. Ann Surg Oncol 21: 2028-2035, 2014.

22. Ishibashi Y, Tsujimoto H, Hiraki S, Kumano I, Yaguchi Y, Horiguchi $\mathrm{H}$, Nomura $\mathrm{S}$, Ito $\mathrm{N}$, Shinto $\mathrm{E}$, Aosasa S, et al: Prognostic value of preoperative systemic immunoinflammatory measures in patients with esophageal cancer. Ann Surg Oncol 25: 3288-3299, 2018.

23. Forrest LM, McMillan DC, McArdle CS, Angerson WJ and Dunlop DJ: Evaluation of cumulative prognostic scores based on the systemic inflammatory response in patients with inoperable non-small-cell lung cancer. Br J Cancer 89: 1028-1030, 2003.

24. Ishibashi $\mathrm{Y}$, Tsujimoto $\mathrm{H}$, Yaguchi $\mathrm{Y}$, Kishi $\mathrm{Y}$ and Ueno $\mathrm{H}$ : Prognostic significance of systemic inflammatory markers in esophageal cancer: Systematic review and meta-analysis. Ann Gastroenterol Surg 4: 56-63, 2019.

25. Ignacio de Ulíbarri J, González-Madroño A, de Villar NG, González P, González B, Mancha A, Rodríguez F and Fernández G: CONUT: A tool for controlling nutritional status. First validation in a hospital population. Nutr Hosp 20: 38-45, 2005.

26. Toyokawa T, Kubo N, Tamura T, Sakurai K, Amano R, Tanaka H, Muguruma K, Yashiro M, Hirakawa K and Ohira M: The pretreatment controlling nutritional status (CONUT) score is an independent prognostic factor in patients with resectable thoracic esophageal squamous cell carcinoma: Results from a retrospective study. BMC Cancer 16: 722, 2016.

This work is licensed under a Creative Commons Attribution-NonCommercial-NoDerivatives 4.0 International (CC BY-NC-ND 4.0) License. 